\title{
Corrosion Behavior of 316 Stainless Steel Exposed to a Simulated Salt lake Atmospheric Environment under UV Illumination
}

\author{
Mingxiao Guo ${ }^{1,2}$, Xiao Lu ${ }^{1,2}$, Junrong Tang ${ }^{1,2}$, Chen Pan ${ }^{2, *}$, Zhenyao Wang, ${ }^{2, *}$ \\ ${ }^{1}$ School of Materials Science and Engineering, University of Science and Technology of China, \\ Shenyang 110016, China \\ ${ }^{2}$ Institute of Metal Research, Chinese Academy of Sciences, Shenyang 110016, China \\ "E-mail: cpan@imr.ac.cn, zhywang@imr.ac.cn
}

doi: $10.20964 / 2021.04 .10$

Received: 16 October 2020 / Accepted: 28 December 2020 / Published: 28 February 2021

\begin{abstract}
In this study, the corrosion mechanism of 316 stainless steel subjected to wet-dry cyclic accelerated corrosion test in a simulated salt lake atmosphere under ultraviolet (UV) illumination was investigated. The corrosion mechanism was investigated by analyzing the corrosion morphologies, corrosion products, in-situ electrochemical impedance spectroscopy (EIS) with micro-distance electrodes and Mott-Schottky measurements. The results revealed that UV illumination inhibited the corrosion rate of the 316 stainless steel with an increase in the corrosion time. In addition, UV illumination had no significant effect on the type of corrosion products but changed the relative amount of the corrosion products. Furthermore, the corrosion process of the 316 stainless steel under UV illumination was affected by the photovoltaic effect of the semiconductor corrosion products.
\end{abstract}

Keywords: Stainless steel; Atmosphere corrosion; In-situ EIS; Photovoltaic effect; Semiconductor

\section{$\underline{\text { FULL TEXT }}$}

(C) 2021 The Authors. Published by ESG (www.electrochemsci.org). This article is an open access article distributed under the terms and conditions of the Creative Commons Attribution license (http://creativecommons.org/licenses/by/4.0/) 